\title{
Survival of Split Thickness Skin Graft in Diabetic and Non-diabetic Wound Management
}

\author{
MARAMREDDY REVANTH, SHIBUMON MADHAVAN MUNDUNADACKAL,
}

B.K.SHIVAPRASAD RAI, SUNILKUMAR SAJJAN, PULLAREDDY SEELAM

\section{ABSTRACT}

Introduction: Split skin grafting is widely used surgical procedure for the treatment of ulcers. Graft survival depends on number of factors like vascularity, wound infection etc. diabetes is associated with endothelial dysfunction, neuropathy, wound infection which collectively affect the graft survival.

Aim: To compare the amount of graft uptake, the post operative complications and survival of split thickness skin graft in diabetic and non diabetic wound management.

Materials and Methods: In our prospective nonrandomized comparative study total 104 patients with ulcer were included of which 52 were diabetic and 52 were non-diabetic. All of them underwent split skin grafting as part of their wound management. Comparison was made between two groups in terms of amount of graft uptake, post operative wound infection, re-ulceration, revisional surgery, donor site infection.
Results: Average wound surface area in diabetic group is $42.31 \mathrm{~cm}^{2}$ and average graft uptake is $23.67 \mathrm{~cm}^{2}$, in non-diabetic group average wound surface area is 78.06 $\mathrm{cm}^{2}$ and average graft uptake is $64.06 \mathrm{~cm}^{2}$. Compared with non-diabetics, diabetics have significantly less graft uptake $(p<0.001)$. out of 52 patients in diabetic group 10(19.3\%) underwent revisional surgery, out of 52 patients in non-diabetic group $2(3.85 \%)$ patients underwent revisional surgery ( $p$ value is $<0.05$ ) which is statistically significant. $3(5.8 \%)$ out of 52 patients in diabetic group developed re-ulceration, $1(1.9 \%)$ out of 52 in non-diabetic group developed re-ulceration ( $p$ $>0.3$, not significant). $13(25 \%)$ out of 52 in diabetic group developed post operative graft infection, $7(13.5 \%)$ out of 52 in non-diabetic group developed graft infection ( $p$ $>0.1$, not significant). None of the patients in the study developed donor site infection.

Conclusion: Diabetes is associated with poor graft survival and high post operative complication rates in patients undergoing split skin grafting.

\section{INTRODUCTION}

Split thickness skin graft (STSG) is a routinely used surgical procedure for treatment of ulcers which involves transfer of epidermis and part of the dermis from donor area to the recipient area. Split-thickness skin grafting is an age old plastic surgery procedure which is in use since $3000 \mathrm{BC}$ in India for traumatic facial wounds. Though it was initially used for facial reconstruction, STSG is now commonly employed in reconstruction of burn wounds and to close chronic non-healing ulcers which are commonly seen in diabetic population. Survival of STSG depends on the vascularity of the recipient site. Presence of infection at the recipient site adversely affects the survival of graft.
Uptake of STSG takes place in three phases namely imbibition, revascularization and organization. Graft will securely adhere to the recipient bed by 10 to 14 days. Sensations return to the graft over time, pain is the first sensation to return within 4 to 5 weeks after grafting.

STSG in diabetic patients poses special concerns like the presence of neuropathy, endothelial dysfunction, and increased susceptibility to infection. Endothelial dysfunction leads to microvascular disruption that is preferably seen in kidneys, eyes and distal extremities. Neuropathy is another significant problem because the patients cannot appreciate pain and most of the times not aware of the severity of their wound until the infection extend more proximally. Diabetic 
patients are at an increased risk for wound infection. All these factors collectively influence the graft survival in diabetics.

This study is aimed to ascertain the survival of split-thickness skin graft in diabetic wounds and its reported risks and complications.

\section{MATERIALS AND METHODS}

This is a prospective comparative study conducted in the constituent teaching hospitals of Kasturba Medical College Mangalore, Manipal University from December 2013 to July 2015. Institutional ethics committee permission was obtained. Total 104 patients were studied over a period of 1 year 8 months of which 52 were diabetics and 52 were nondiabetics. Subjects were selected by purposive sampling, a type of non-probability sampling method after applying inclusion and exclusion criteria.

\section{Inclusion Criteria}

All patients above the age of 18 years, undergoing SSG were included in the study. Wounds with healthy granulation tissue with no bacterial growth or scanty growth on culture were included in the study.

\section{Exclusion Criteria}

Patients with age less than 18 years were excluded. Patients with peripheral arterial disease, HIV, malignancies, tuberculosis which hinders wound healing were excluded from the study. Wounds with moderate or heavy growth of organisms on culture were excluded.

Informed consent was obtained from all the subjects in the study. Patients who were diagnosed with diabetes and on medication and patients who were diagnosed recently with fasting sugar of $>126 \mathrm{mg} / \mathrm{dl}$ or random blood sugar of $>200$ $\mathrm{mg} / \mathrm{dl}$ were included in the diabetic group. All the patients underwent STSG for the management of ulcer after following standard criteria. All diabetic patients have their blood sugars under control before the procedure. Out of 52 patients in diabetic group 12 had hypertension, 7 had varicose veins. Out of 52 non-diabetic patients 8 had hypertension, 3 had varicose veins. All the patients with varicose veins were treated with surgery (Trendlenberg procedure with or without perforator ligation) before STSG. 6 of 52 patients in diabetic group were smokers, while 4 of 52 in non-diabetic group, were smokers.

Results were compared between two groups in terms of amount of graft uptake, post operative graft infection, need for revisional surgery, re-ulceration, donor site infection. Amount of graft uptake was calculated by measuring surface area of the wound that was grafted and area of the graft that was taken at fourteenth post-operative day. Surface area was measured with standard manual method of transparent sheet and graph paper [1]. All the patients in the study were followed for a period of 6 months.

\section{RESULTS}

Total 104 patients were studied with 52 in each arm. Mean age of diabetic group was 51.8 years and that of non-

\begin{tabular}{|c|c|c|c|}
\hline \multirow{2}{*}{ SEX } & & & \multirow[b]{2}{*}{ Total } \\
\hline & DM & Non DM & \\
\hline \multirow[t]{2}{*}{$F$} & 10 & 11 & 21 \\
\hline & $19.2 \%$ & $21.2 \%$ & $20.2 \%$ \\
\hline & 42 & 41 & 83 \\
\hline & $80.8 \%$ & $78.8 \%$ & $79.8 \%$ \\
\hline \multirow[t]{2}{*}{ Total } & 52 & 52 & 104 \\
\hline & $100.0 \%$ & $100.0 \%$ & $100.0 \%$ \\
\hline
\end{tabular}

[Table/Fig-1: Shows sex distribution in diabetic and non-diabetic groups.

F-female, M-male, DM-diabetes mellitus

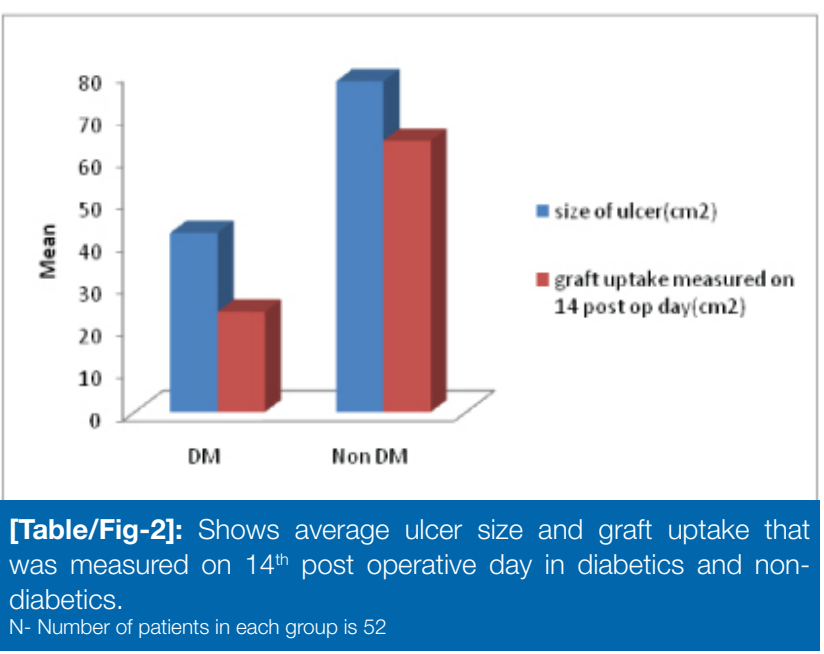

\begin{tabular}{|c|c|c|c|c|c|c|c|}
\hline & & \multirow[t]{2}{*}{$\mathrm{N}$} & \multirow[t]{2}{*}{ Mean } & \multirow[t]{2}{*}{$\mathrm{SD}( \pm)$} & \multirow[t]{2}{*}{ Median (IQR) } & \multicolumn{2}{|c|}{ Wilcoxon signed rank test } \\
\hline & & & & & & Value & $p$ \\
\hline \multirow[t]{2}{*}{ DM } & \multirow{2}{*}{$\begin{array}{l}\text { Size of ulcer }\left(\mathrm{cm}^{2}\right) \text { graft uptake } \\
\text { (measured on } 14^{\text {th }} \text { post op day) }\end{array}$} & \multirow[t]{2}{*}{52} & 42.31 & 21.89 & $36(27-48.25)$ & \multirow[t]{2}{*}{7.430} & \multirow{4}{*}{$\begin{array}{c}\mathrm{p}<0.001 \\
\mathrm{HS}\end{array}$} \\
\hline & & & 23.67 & 15.97 & $21.5(16-31.75)$ & & \\
\hline \multirow[t]{2}{*}{ Non-DM } & \multirow{2}{*}{$\begin{array}{l}\text { size of ulcer }\left(\mathrm{cm}^{2}\right) \text { graft uptake } \\
\text { (measured on } 14^{\text {th }} \text { post op day) }\end{array}$} & \multirow[t]{2}{*}{52} & 78.06 & 58.58 & 59(38.25-93.75) & \multirow[t]{2}{*}{6.360} & \\
\hline & & & 64.06 & 45.88 & $52(31.5-81)$ & & \\
\hline
\end{tabular}

[Table/Fig-3]: Shows mean ulcer size and graft uptake in diabetic and non-diabetic groups. significance of difference in graft uptake between two groups was calculated using Wilcoxon signed rank test.

$\mathrm{N}$-number of patients, HS- Highly Significant 
diabetic group is 39.94 years ( $p<0.001$, significant).Sex distribution was shown in [Table/Fig-1]. Average wound size in diabetic group was $42.3 \mathrm{~cm}^{2}$ and $78.06 \mathrm{~cm}^{2}$ in nondiabetic group [Table/Fig-2]. Average graft uptake was 23.67 $\mathrm{cm}^{2}$ in diabetic group and $64.06 \mathrm{~cm}^{2}$ in non diabetic group ( $p<0.001$ significant) [Table/Fig-3]. None of the patients in the study developed donor site infection.13(25\%) out of 52 in diabetic group developed post operative graft infection, $7(13.5 \%)$ out of 52 in non-diabetic group developed post

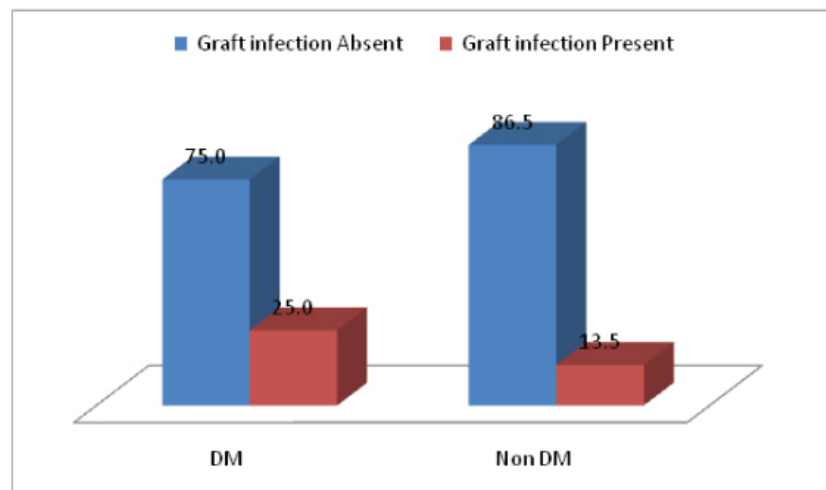

[Table/Fig-4]: Shows percentage of post operative graft infection in diabetic and non-diabetic groups. Total number of patients in each group is 52

\begin{tabular}{|l|r|r|r|}
\hline \multirow{2}{*}{ Duration of diabetes } & \multicolumn{2}{|c|}{$\begin{array}{c}\text { post op graft } \\
\text { infection }\end{array}$} & \multirow{2}{*}{} \\
\cline { 2 - 4 } & \multicolumn{1}{|c|}{ Absent } & \multicolumn{1}{|c|}{ Present } & \multicolumn{1}{c|}{ Total } \\
\hline \multirow{2}{*}{$<5 y$ rs } & 33 & 4 & 37 \\
& $89.2 \%$ & $10.8 \%$ & $100.0 \%$ \\
& $84.6 \%$ & $30.8 \%$ & $71.2 \%$ \\
\hline 5 yrs and above & 6 & 9 & 15 \\
& $40.0 \%$ & $60.0 \%$ & $100.0 \%$ \\
& $15.4 \%$ & $69.2 \%$ & $28.6 \%$ \\
\hline Total & 39 & 13 & 52 \\
& $75.0 \%$ & $25.0 \%$ & $100.0 \%$ \\
& $100.0 \%$ & $100.0 \%$ & $100.0 \%$ \\
\hline
\end{tabular}

[Table/Fig-5]: Shows significance of duration of diabetes in development of post operative graft infection. Diabetic patients of more than 5 years duration were compared with those of less than 5 years in terms of graft infection $p$ value is $<0.001$, using chi-square test

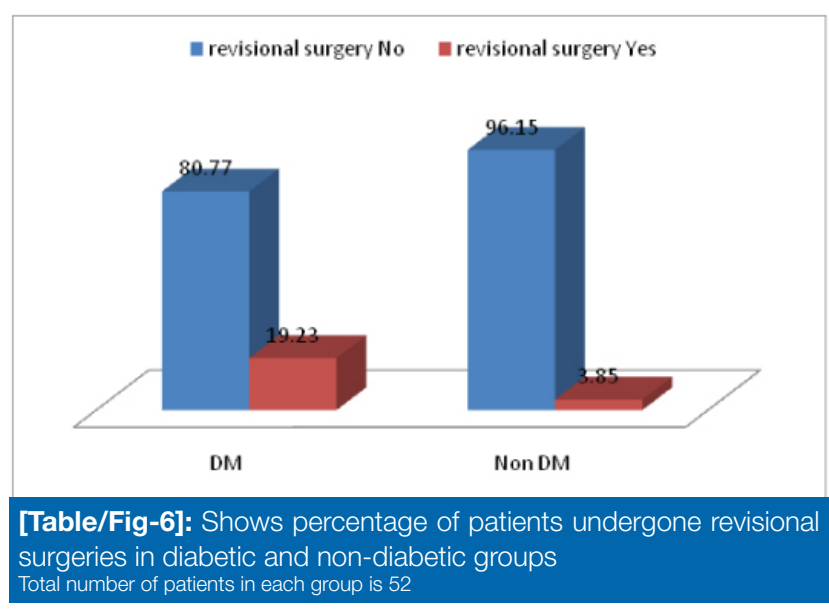

operative graft infection( $p>0.1)$ [Table/Fig-4]. Though post operative wound infection rate was high in diabetics, it is not statistically significant. If duration of diabetes was taken into consideration, patients with diabetes for five or more years had significant post operative graft infection compared to non-diabetics and diabetics of less than five years $(p<0.001)$ [Table/Fig-5]. Significant number of patients underwent revisional surgery in diabetic group (10 out of 52) in the form of wound debridement, re-grafting, amputation etc compared to diabetic group (2 out of 52) ( $p<0.02)$ [Table/Fig-6]. 3 of the diabetic patients in the study developed re-ulceration at the graft site within 6 months of follow up, while only 1 in non-diabetic group developed re-ulceration $(p>0.3)$ which is not significant [Table/Fig-7]. Complete graft failure was noted in 7 of the diabetic patients, while 1 patient in non-diabetic group had complete graft failure ( $p<0.03$, significant). Causative organisms for post-operative graft infection were mentioned in [Table/Fig-8]. Various types of revisional surgeries that patients underwent after skin grafting were shown in [Table/Fig-9]. [Table/Fig-10-14] shows outcomes of split skin grafting in diabetics and non-diabetics.

\begin{tabular}{|c|c|c|c|}
\hline & Non-diabetic & Diabetic & $p$-value \\
\hline Mean age(yrs) & 39.94 & 51.8 & $<0.001(\mathrm{~S})$ \\
\hline Graft infection & 7 & 13 & $0.135(\mathrm{~N} \mathrm{~S})$ \\
\hline Revisional surgery & 2 & 10 & $0.014(\mathrm{~S})$ \\
\hline Re-ulceration & 3 & 1 & $0.309(\mathrm{~N} \mathrm{~S})$ \\
\hline Donor site infection & Nil & Nil & - \\
\hline Complete graft failure & 1 & 7 & $0.025(S)$ \\
\hline \multicolumn{4}{|c|}{$\begin{array}{l}\text { [Table/Fig-7]: Shows various complications following split skir } \\
\text { grafting between diabetic and non-diabetic groups } \\
\text { S- significant N S- not significant }\end{array}$} \\
\hline
\end{tabular}

\begin{tabular}{|c|c|c|c|}
\hline \multirow{2}{*}{ Post operative graft infection } & \multicolumn{2}{|c|}{$\mathrm{DM}$} & \multirow[b]{2}{*}{ Total } \\
\hline & DM & Non DM & \\
\hline \multirow[t]{2}{*}{ E.coli } & 1 & 0 & 1 \\
\hline & $7.7 \%$ & $.0 \%$ & $5.0 \%$ \\
\hline \multirow[t]{2}{*}{ Klebsiella sp } & 1 & 0 & 1 \\
\hline & $7.7 \%$ & $.0 \%$ & $5.0 \%$ \\
\hline \multirow[t]{2}{*}{ Pseudomonas aeruginosa } & 6 & 5 & 11 \\
\hline & $46.2 \%$ & $71.4 \%$ & $55.0 \%$ \\
\hline \multirow[t]{2}{*}{ Staphylococcus aureus } & 5 & 2 & 7 \\
\hline & $36.5 \%$ & $28.6 \%$ & $35.0 \%$ \\
\hline \multirow[t]{2}{*}{ Total } & 13 & 7 & 20 \\
\hline & $100.0 \%$ & $100.0 \%$ & $100.0 \%$ \\
\hline
\end{tabular}

[Table/Fig-8]: Shows frequency of different organisms grown from post operative graft infection in diabetics and non-diabetics. Total number of patients in each group are 52

\begin{tabular}{|l|l|l|}
\hline Type of Revisional Surgery & Non-Diabetic & Diabetic \\
\hline Wound Debridement & 2 & 4 \\
\hline Re-Grafting & Nil & 5 \\
\hline Amputation & Nil & 1 \\
\hline Total & $2(3.85 \%)$ & $10(19.2 \%)$ \\
\hline
\end{tabular}

[Table/Fig-9]: Shows different types of revisional surgeries done in diabetic and non-diabetic groups.

Total number of patients in each group are 52 

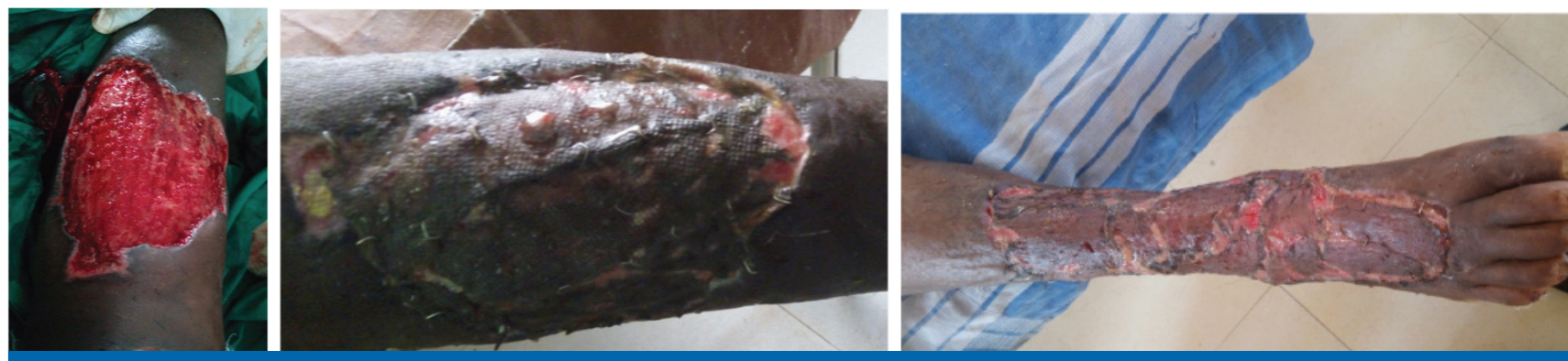

[Table/Fig-10-12]: Show healthy wound over anterior aspect of left leg in a non-diabetic patient before and after grafting respectively. Shows good graft uptake in a diabetic patient with wound over right leg.

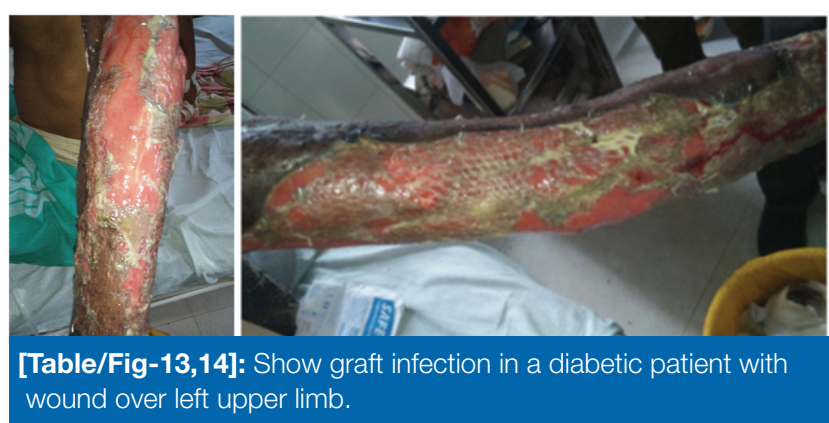

\section{DISCUSSION}

Diabetes mellitus is characterized by hyperglycemia that is caused due to improper secretion of insulin or defective action of insulin on cells or both. Diabetes is the most common metabolic disorder with a prevalence of around 62 million cases in India [2].

Diabetes is associated with long term disease specific microangiopathy which leads to complications like nephropathy, neuropathy, and retinopathy. This microvascular dysfunction in diabetes will also affect adversely, the process of wound healing. Wound healing is impaired in diabetic patients and it is due to microvascular disease causing tissue hypoxia, peripheral neuropathy, and abnormal inflammatory and cellular pathways which predispose to infection in foot ulcers [3-6]. Small fiber dysfunction is an early feature in patients with type 2 diabetes and it has been implicated in delayed wound healing $[7,8]$. Wound healing is debilitated by several factors such as under-perfusion caused by reduced tissue response to the injury, dependent edema caused by a defective venoarteriolar reflex and an increase in capillary permeability $[9,10]$. Many studies on humans showed no reduction in the density of skin capillaries. This result implies that microvascular function might be so abnormal that it reduces blood flow to the tissue even though there is no reduction in overall vascular density in patients suffering from diabetes [11,12]. Recent studies on diabetic animals revealed a reduction in Vascular Endothelial Growth Factor (VEGF) which is known to promote angiogenesis and a tropical application of VEGF improved would healing $[13,14]$.
Split skin grafting is commonly employed surgical method in the management of ulcers, which requires angiogenesis for its survival. As diabetic patients with microangiopathy have poor angiogenesis, they are at risk for graft failure. There are very few studies in the literature showing effect of diabetes on split skin graft survival.

Mowlavi et al., [15] reported decreased graft take in individuals with hyperglycemia; however, the authors used only preoperative serum glucose level, rather than duration of diabetes, in their analyses and did not distinguish between patients with and without the co-morbidities associated with diabetes.

Ramanujam et al., [16] retrospectively reviewed 203 patients who underwent STSG to ascertain the differences in healing time, necessity to perform revisional surgery and postoperative infections. With the help of this data, they developed a predictive model that can identify diabetic patients who are likely to have a successful STSG. Diabetic patients with preexisting co-morbidities were observed to have a higher risk of delayed healing, more susceptible to post-operative infections and prone to revisional surgery compared to nondiabetic patients or diabetic patients without co-morbidities. However, there were no significant differences in outcome between diabetic patients without co-morbidities and nondiabetic patients. Method of healing time measurement was not explained in this study. Only co-morbidities were considered in this study but not the duration of diabetes [1719].

In our study duration of diabetes and its impact on skin graft survival was considered and amount of graft survival was compared rather than duration of graft uptake. This study shows that post operative complications are significantly high in diabetics of longer duration. Rate of complete graft failure is significantly high in diabetic group.

In this study there is significant difference in mean age of diabetic and non-diabetic groups, furthermore, glycosylated hemoglobin levels, chronic kidney disease, blood urea levels, and serum creatinine concentration represent modifiable 
characteristics that may need to be addressed when selecting patients for STSG in diabetic ulcers.

\section{CONCLUSION}

This study demonstrates that split skin graft uptake was significantly less and rates of revisional surgery were significantly high in diabetic patients. Rate of complete graft failure was significantly high in diabetics. There is no significant difference in donor site infection and re-ulceration between diabetics and non-diabetics. Further studies required to support this data, complications of diabetes like chronic kidney disease were not considered, nutritional status of patients like serum albumin was not included in the study.

\section{REFERENCES}

[1] Thawer HA, Houghton PE, Woodbury MG, Keast D, Campbell K. A comparison of computer assisted and manual wound size measurement. Ostomy Wound Manage. 2002;48(10):46-53

[2] Kaveeshwar SA, Cornwall J. The current state of diabetes mellitus in India. The Australasian medical journal. 2014, 7(1): 45-48. - ncbi.nlm.nih.gov

[3] Pham H, Armstrong DG, Harvey C, Harkless LB, Giurini JM, Veves A: Screening techniques to identify people at high risk for diabetic foot ulceration: a prospective multicenter trial. Diabetes Care. 2000; 23(5): 606-11. PMID:10834417

[4] Rose JF, Giovinco N, Mills JL, Najafi B, Pappalardo J, Armstrong DG . Split-thickness skin grafting the high-risk diabetic foot. J Vasc Surg. 2014;59(6):1657-63.

[5] Young MJ, Bennett JL, Liderth SA, Veves A, Boulton AJ, Douglas JT: Rheological and microvascular parameters in diabetic peripheral neuropathy. Clin Sci (Colch). 1996;90:183-87. Medline

[6] Flynn MD, Tooke JE: Diabetic neuropathy and the microcirculation. Diabet Med.1995:12 : 298-301. Medline

[7] Vinik Al, Erbas T, Stansberry KB, Pittenger GL: Small fiber neuropathy and neurovascular disturbances in diabetes mellitus. Exp Clin Endocrinol Diabetes. 2001: $109: 451-73$.
[8] Krishnan ST, Rayman G: The LDIflare: a novel test of C-fiber function demonstrates early neuropathy in type 2 diabetes. Diabetes Care. 2004;27: 2930-35.

[9] Christopherson K. The impact of diabetes on wound healing: implications of microcirculatory changes. $\mathrm{Br} J$ Community Nurs. 2003;8: S6-13.

[10] Greenhalgh DG. Wound healing and diabetes mellitus. Clin Plast Surg. 2003;30:37-45.

[11] Jaap AJ, Shore AC, Stockman AJ, Tooke JE: Skin capillary density in subjects with impaired glucose tolerance and patients with type 2 diabetes. Diabet Med. 1996;13:160-64.

[12] Takabayashi $Y$, Ishihara $M$, Sumi $Y$, Takikawa $M$ et al. Plateletrich plasma-containing fragmin-protamine micro-nanoparticles promote epithelialization and angiogenesis in split-thickness skin graft donor sites: J of Surg Research. 2015;193:483-91.

[13] Frank S, Hubner G, Breier G, Longaker MT, Greenhalgh DG, Werner S. Regulation of vascular endothelial growth factor expression in cultured keratinocytes: implications for normal and impaired wound healing. J BioChem. 1995;270:12607-13.

[14] Galiano RD, Tepper OM, Pelo CR, Bhatt KA, Callaghan M, Bastidas $\mathrm{N}$ et al: Topical vascular endothelial growth factor accelerates diabetic wound healing through increased angiogenesis and by mobilizing and recruiting bone marrow-derived cells. Am J Pathol. 2004; 164: 1935-47.

[15] Mowlavi A, Andrews K, Lille S, Verhulst S, Zook EG, Milner S. The effects of hyperglycemia on skin graft survival in the burn patient. Ann Plast Surg. 2000;45:629-32.

[16] Ramanujam CL, Han D, Fowler S, Kilpadi K, Zgonis T. Impact of diabetes and co-morbidities on split-thickness skin grafts for foot wounds. J Am Podiatr Med Assoc. 2013;103(3):223-32.

[17] Sonker A, Dubey A, Bhatnagar A, Chaudhary R. Platelet growth factors from allogeneic platelet-rich plasma for clinical improvement in split-thickness skin graft. Asian Journal of Transfusion Science. 2015;9(2):155-58.

[18] Schade VL, Roukis TS . Use of platelet-rich plasma with splitthickness skin grafts in the high-risk patient. Foot Ankle Spec. 2008;1(3):155-59.

[19] Bekara F, Herlin C, Ayestaray B, Lacoste-Collin L, et al. Suction drain assisted split thickness skin grafting: A simple procedure to improve skin graft take. Plast Reconstr Surg. 2015 ;135(1):240e-1e.
AUTHOR(S):
1. Dr. Maramreddy Revanth
2. Dr. Shibumon Madhavan Mundundackal
3. Dr. B.K. Shivaprasad Rai
4. Dr. Sunil Kumar Sajjan
5. Dr. Pullareddy Seelam

\section{PARTICULARS OF CONTRIBUTORS:}

1. Postgraduate, Department of General Surgery, KMC, Mangalore, Karnataka, India.

2. Associate Professor, Department of General Surgery, KMC, Mangalore, Karnataka, India.

3. Professor, Department of General Surgery, KMC, Mangalore, Karnataka, India.
4. Postgraduate, Department of General Surgery, KMC, Mangalore, Karnataka, India.

5. Postgraduate, Department of General Surgery, KMC, Mangalore, Karnataka, India.

\section{NAME, ADDRESS, E-MAIL ID OF THE CORRESPONDING AUTHOR:}

Dr. Maramreddy Revanth, Resident, Department of General Surgery, Kasturba Medical College, Mangalore, Karnataka-575001, India.

E-mail: revanthmbbs@gmail.com

FINANCIAL OR OTHER COMPETING INTERESTS:

None. Date of Publishing: Jan 05, 2016 